\title{
A study on the assessment of retreatment tuberculosis patients attending the DOTS centre in Sikkim, India from 2002-2010
}

\author{
Karma G. Dolma1* , Luna Adhikari ${ }^{1}$, Peggy Dadul ${ }^{2}$, Tsering Laden², Lalita Singhi ${ }^{2}$ and J. Mahanta ${ }^{3}$ \\ *Correspondence: gyur_skyscraper@hotmail.com \\ 'Sikkim Manipal Institute of Medical Sciences (SMIMS) and Central Referral Hospital (CRH) 5th Mile Tadong, Gangtok, Sikkim, India. \\ ${ }^{2}$ Department of Healthcare, Family welfare and Human services (HC, FW\&HS), Govt of Sikkim, India. \\ ${ }^{3}$ Regional Medical Research Centre (RMRC), ICMR- North East Region, Lahowal, Dibrugarh, Assam, India.
}

\begin{abstract}
Background: Sikkim, India has maintained the global targets of $70 \%$ detection and $85 \%$ cure of the new smear positive cases since 2003; however, the rate of retreatment cases have become a matter of concern. An accurate analysis of the retreatment cases and their treatment outcome is needed to ascertain the strengths and weaknesses in the management of retreatment.

Methods: Diagnosis, classification, chemotherapy and outcomes following treatment were noted. Treatment details were updated regularly and the patient's final outcome was recorded at the end of their treatment. Annual notification and treatment outcome analysis was conducted for retreatment cases as a whole as well as for each sub-category of retreatment independently. The Chi square test was used to assess the statistical significance of each rate ratio. A statistical test was considered significant when the $\mathrm{P}$ value was $<0.005$.

Results and discussion: Overall relapse cases (63.8\%) were the most common; followed by failure cases (20.8\%) and treatment after default cases (15.2\%). Overall cohort analysis of retreatment cases shows treatment cure rate of $62.4 \%$ and treatment failure of $22.1 \%$. Stratified cohort analysis highlights treatment cure rate of $70.4 \%$ and $34.1 \%$ among relapses and failures. The treatment failure rate for failures was $45.2 \%$, strongly suggesting multi drug resistance (MDR); this highlights the need to implement measures to reduce the number of failures. Among the treatment after default the default rate was 6.7\%; strict treatment adherence and positive patient's attitude and behaviour towards the disease is the main solution to avoid defaulting.

Conclusion: In the retreatment category relapse cases were the most common retreatment category however these patients were more likely to be cured with the Category II retreatment regimen; patients who failed the Category I treatment were most likely to wound up as failures on the Category II retreatment regimen, and first time defaulters had a significant risk of defaulting from the Category II retreatment regimen. Controlling the need for retreatment is the best known strategy, apart from this continuous monitoring, adherence and treatment completion is essential in order to improve tuberculosis control.
\end{abstract}

Keywords: Retreatment category, failure, relapse, treatment after default and tuberculosis

\section{Introduction}

Tuberculosis (TB) remains a worldwide healthcare concern and is a major health problem in Sikkim, India. Based on the findings and recommendation of the 1992 review Committee of National Tuberculosis Programme (NTP), Government of India revised its strategy and introduced Revised National Tuberculosis Control Programme (RNTCP) in October 1993. Sikkim is a small hilly north eastern state of India. It is fully covered under RNTCP from $1^{\text {st }}$ March 2002. With the implementation of RNTCP; Sikkim has had a progressive increase and maintained the global targets of $85 \%$ cure of new smear positive patients and detection of at least $70 \%$ of the new smear positive cases since 2003 [1], these indicators are tantamount with good programme performance however, the treatment outcome of patients on retreatment has remained unchanged over the years; the treatment failure of the failure group has increased from $40.8 \%$ in 2009 to $50 \%$ in 2010, similarly the treatment failure in default group has increased from $15.6 \%$ in 2009 to $22.4 \%$ in 2010 [2,3], hence, the study aims to find out the effectiveness of the DOTS program by analyzing the retreatment category and their treatment outcome. According to the recommendations of the World
Health Organization (WHO), patients with recurrent tuberculosis are defined as retreatment cases and are eligible for the standardized category II treatment regimen [4]. An accurate analysis of all the information recorded on the treatment outcome of retreatment cases is needed to identify strengths and weaknesses in the management of retreatment cases and to discuss possible measures for improving tuberculosis care in this group of patients. Under the RNTCP, the percentage of smear positive retreatment cases out of all smear positive cases is $24 \%$ [5]. According to the RNTCP data for 2009, the cure rate among the retreatment group was $64 \%$, mortality rate $7.8 \%$, failure rate $5.6 \%$ and default rate about $14.1 \%$ [2]. Despite of the differences in the outcomes of the retreatment category, they are however, treated with the same regimen under the program. Outcome after retreatment is normally worse and costly because of the cost of extended treatment and second line drugs and emergence of drug resistance. The objective of the study was to describe and discuss notification and treatment outcome data of retreatment cases that underwent category II treatment regimen during the period 2002-2010 in Sikkim, India. Cohort analysis were performed on the group of 
Dolma et al. Research Journal of Infectious Diseases 2013,

retreatment cases as a whole as well on each sub-category of retreatment cases independently.

\section{Materials and methods}

Sikkim is administratively divided into 4 districts, 5 TB units, 20 Designated Microscopy Centres, and 698 DOTS centres. According to the national guidelines, TB patients receiving the category II treatment regimen are registered and monitored in three different sub-categories, namely.

\section{Relapse}

A TB patient who was declared cured or treatment completed by a physician, but who reports back to the health service and is now found to be sputum smear-positive.

\section{Treatment after default}

A TB patient who received anti-tuberculosis treatment for one month or more from any source and returns to treatment after having defaulted, i.e., not taken anti-TB drugs consecutively for two months or more, and is found to be sputum smearpositive.

\section{Failure}

Any TB patient who is smear-positive at 5 months or more after starting treatment. These case definitions did not change over the study period. All smear positive confirmed pulmonary tuberculosis patients who were given the category II treatment regimen from 2002 to 2010 in the RNTCP of Sikkim were enrolled in this retrospective study. A standardized retreatment regimen was used consisting of isoniazid $(H)$, rifampicin $(R)$, pyrazinamide ( $\mathrm{Z}$ ) ethambutol (E) and streptomycin (S) $\left[2 \mathrm{H}_{3} \mathrm{R}_{3} \mathrm{Z}\right.$ $\left.{ }_{3} \mathrm{E}_{3} \mathrm{~S}_{3}+1 \mathrm{H}_{3} \mathrm{R}_{3} \mathrm{Z}_{3} \mathrm{E}_{3}+5 \mathrm{H}_{3} \mathrm{R}_{3} \mathrm{E}_{3}\right]$. The number before the letters refer to the number of months of treatment and the subscript after the letters refers to the number of doses per week. Diagnosis, classification and chemotherapy were performed according to the RNTCP guidelines [6], and outcomes following treatment were noted. The records of all patients who receive antitubercular treatment are kept in the tuberculosis register at the tuberculosis unit (TU). Treatment details were updated regularly and the patients' final outcome was recorded at the end of their treatment. The TU compiles information about all TB patients entered in the unit register. The TU prepares report for case detection and treatment outcome quarterly and submits the report to the district tuberculosis officer (DTO), who is responsible for compiling the reports from all the units and submits them, to the state tuberculosis officer (STO). STO compiles reports from all districts and submits them to the central TB division.

Annual notification and treatment outcome analysis was conducted for retreatment cases as a whole as well as for each sub-category of retreatment independently for the years 2002-2010. Rate ratios were used to assess the differences in treatment outcome between retreatment sub-categories. The Chi square test was used to assess the statistical significance of each rate ratio. A statistical test was considered significant when $\mathrm{P}$ was $<0.005$.

As the study was anonymous and retrospective data analysis, no ethical approval was sought except the administrative clearance was obtained from the state TB cell, Government of Sikkim, state task force (RNTCP) and PhD review committees of Sikkim Manipal University, India.

\section{Results}

During the study from 2002 to 2010 in all the four districts of Sikkim; a total of 6827 cases were registered for pulmonary tuberculosis. Out of these cases, $6051(88.6 \%)$ were cured; $205(3 \%)$ had died; $399(5.8 \%)$ had failed; $124(1.8 \%)$ had defaulted and $48(0.7 \%)$ were lost to follow up. A total of 1855 pulmonary tuberculosis patients were put on Category II retreatment regime (1185 relapse cases, 387 failures and 283 treatment after default). The total retreatment rate of Sikkim is $1855(27.1 \%)$. Over the years, we observed that relapse cases $1185(63.8 \%)$ were found to be the most common in the retreatment category; followed by failure cases $387(20.8 \%)$ and treatment after default cases $283(15.2 \%)$. The overall cohort analysis which presents annual treatment outcomes of retreatment cases considered as a whole, shows treatment cure rate of $62.4 \%$ (range $57.7 \%-65.9 \%$ ), treatment failure of $22.1 \%$ (range $15.4 \%-27.1 \%$ ), mortality rate of $8.71 \%$ (range 6.5\%-14.1\%) and default rate of $4.3 \%$ (range 3.0\%-6.5\%) (Figure 1). However, stratified cohort analysis highlights relevant differences between the three sub-categories of retreatment cases. Among relapses, the treatment success rate was $835(70.4 \%)$ and the treatment failure rate was $185(15.6 \%)$. Among patients who failed the category I treatment regimen, the treatment success rate was only $132(34.1 \%)$; while the treatment failure rate was $175(45.2 \%)$ and the mortality rate was 50(12.9\%). Among those who interrupted one course of treatment and then received the category II treatment regimen the treatment success rate was $190(67.1 \%)$ and the default rate was 19(6.7\%) (Table 1). The comparison of treatment outcome between the sub-categories shows that treatment success rates are significantly higher among the relapse cases than among patients who failed category I $(P<0.005)$ and among those who defaulted from one previous course of anti-tuberculosis treatment $(P<0.005)$ in all the years. Failure rates are also significantly and consistently higher in patients who failed category I treatment than in default cases $(P<0.005$ but in two years), while no clear differences can be demonstrated with relapse cases. Default rates was not found to be significant in patients who defaulted from one previous course of anti-tuberculosis treatment compared to those who failed category I treatment and for those who relapsed, it was found to be significant only in two years (Table 2).

\section{Discussion}

Retreatment cases represent a serious threat to TB control in many settings, and could significantly undermine the overall 


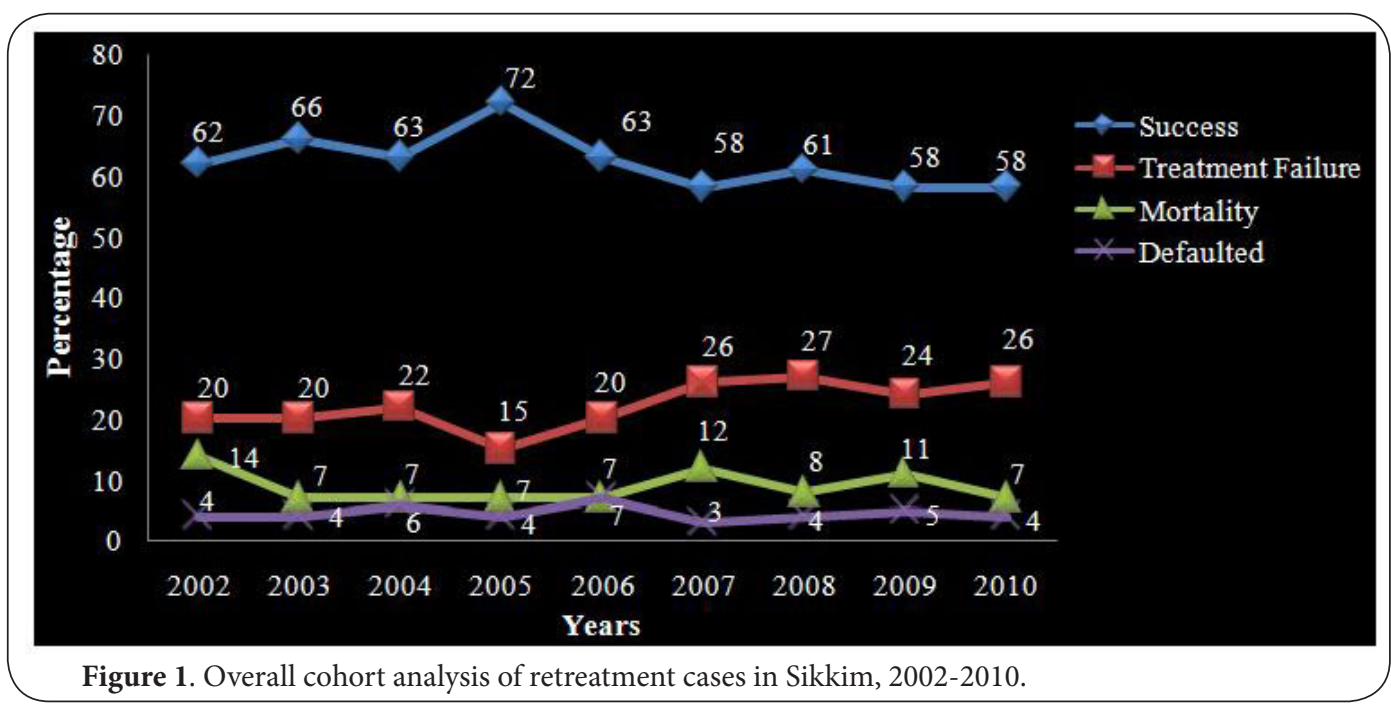

Table 1. Rates of treatment success, failure and default by subcategory of retreatment cases in Sikkim, 2002-2010.

\begin{tabular}{|c|c|c|c|c|c|c|c|c|c|c|c|c|}
\hline \multicolumn{5}{|c|}{ Relapse cases } & \multicolumn{4}{|c|}{ Failure cases } & \multicolumn{4}{|c|}{ Treatment after default cases } \\
\hline Year & Total (n) & Success (\%) & $\begin{array}{l}\text { Treatment Failure } \\
(\%)\end{array}$ & Default (\%) & Total (n) & Success (\%) & $\begin{array}{l}\text { Treatment } \\
\text { Failure (\%) }\end{array}$ & Default (\%) & $\begin{array}{l}\text { Total } \\
\text { (n) }\end{array}$ & Success (\%) & $\begin{array}{l}\text { Treatment } \\
\text { Failure (\%) }\end{array}$ & Default (\%) \\
\hline 2002 & 47 & 70.2 & 14.8 & 2.1 & 11 & 45.4 & 45.4 & - & 27 & 55.5 & 18.5 & 7.4 \\
\hline 2003 & 111 & 71.1 & 12.6 & 5.4 & 32 & 28.1 & 53.1 & 6.2 & 51 & 78.4 & 13.7 & - \\
\hline 2004 & 111 & 65.7 & 20.7 & 5.4 & 38 & 52.6 & 26.3 & 5.2 & 30 & 66.6 & 20.0 & 6.6 \\
\hline 2005 & 169 & 78.1 & 11.2 & 2.9 & 42 & 45.2 & 40.4 & 4.7 & 29 & 75.8 & 3.4 & 10.3 \\
\hline 2006 & 144 & 69.4 & 14.5 & 5.5 & 48 & 37.5 & 43.7 & 4.1 & 22 & 77.2 & - & 18.1 \\
\hline 2007 & 144 & 68.7 & 15.2 & 2.7 & 58 & 22.4 & 58.6 & 5.1 & 25 & 76.0 & 12.0 & - \\
\hline 2008 & 152 & 73.0 & 19.7 & 1.3 & 44 & 20.4 & 56.8 & 6.8 & 29 & 62.0 & 20.6 & 10.3 \\
\hline 2009 & 157 & 67.5 & 19.7 & 4.4 & 51 & 35.2 & 39.2 & 3.9 & 37 & 51.3 & 21.6 & 8.1 \\
\hline 2010 & 150 & 68.0 & 22.6 & 4.0 & 63 & 33.3 & 41.2 & 3.1 & 33 & 60.6 & 15.1 & 6.0 \\
\hline
\end{tabular}

Table 2. Rate ratios of treatment success, treatments failure and default across retreatment categories in Sikkim, $2002-2010$.

\begin{tabular}{|c|c|c|c|c|c|c|}
\hline \multicolumn{3}{|c|}{ Treatment success } & \multicolumn{2}{|c|}{ Treatment Failure } & \multicolumn{2}{|c|}{ Default } \\
\hline Year & Relapse/Failure & Relapse/Treatment after default & Failure/Relapse & $\begin{array}{c}\text { Failure/Treatment after } \\
\text { default }\end{array}$ & $\begin{array}{c}\text { Treatment after default / } \\
\text { Relapse }\end{array}$ & $\begin{array}{c}\text { Treatment after default / } \\
\text { Failure }\end{array}$ \\
\hline 2002 & $38.3^{*}$ & $12.0^{*}$ & 0.16 & 0.00 & 0.00 & 1.00 \\
\hline 2003 & $108.2^{\star}$ & $24.2^{\star}$ & 0.25 & $6.75^{\star}$ & $8.33^{\star}$ & 1.00 \\
\hline 2004 & $58.1^{\star}$ & $58.1^{*}$ & $8.72^{*}$ & 1.125 & 2.25 & 0.00 \\
\hline 2005 & $166.1^{\star}$ & $154.2^{*}$ & 0.05 & $25.0^{*}$ & 0.25 & 0.00 \\
\hline 2006 & $111.2^{\star}$ & $114.9^{*}$ & 0.00 & $38.0^{*}$ & 1.50 & 0.33 \\
\hline 2007 & $129.0^{*}$ & $105.7^{*}$ & $4.32^{*}$ & $48.6^{*}$ & $4.50^{*}$ & 2.66 \\
\hline 2008 & $170.0^{*}$ & $131.2^{*}$ & 0.58 & $20.9^{*}$ & 0.00 & 0.00 \\
\hline 2009 & $122.0^{*}$ & $118.3^{*}$ & $3.92^{*}$ & $8.64^{\star}$ & 1.8 & 0.00 \\
\hline 2010 & $104.0^{*}$ & $107.5^{*}$ & 1.63 & $25.8^{\star}$ & 2.25 & 0.00 \\
\hline
\end{tabular}

${ }^{\star}$ Statistically significant $(\mathrm{P}<0.05)$

success of the DOTS strategy. This article presents an analysis of outcome of anti-tuberculosis treatment of patients who underwent the category II regimen. In our study, the rate of relapse, treatment failure and default cases were $63.8 \%, 20.8 \%$ and $15.2 \%$ respectively. We observed that the largest group who had received previous RNTCP treatment was relapse cases. Chandrasekaran and Mehra have also found higher relapse rates in their studies $[7,8]$. It is also to be mentioned that RNTCP does not follow up on patients for any period of time after successful completion of treatment to determine whether they relapse or not [9]. Similar results have been observed in several other settings such as Korea, Nicaragua and some provinces of China [10-12].

The overall cohort analysis shows conflicting results between the years, Sikkim has shown cure rate of $62.4 \%$ among the retreatment category and are always associated with higher failure rate of $22.1 \%$ and death rate of $8.7 \%$. The chances of high failure rate will have an utmost impact on the 
morbidity and mortality of tuberculosis in the state, causing to be a matter of grave concern. This analysis highlights the need to manage and implement measures to reduce the number of failures. However, the low default rate of $4.3 \%$ determines good supervision of the committed workers of RNTCP by improving the case holding, better performance and effective management of the programme.

On further analysis of treatment outcome by subcategory of retreatment shows good cure rate among the relapse cases and default cases $(70.1 \%$ and $67 \%)$,however, lower that the national data of $74 \%$ and $68 \%$ respectively [13]. Mukherjee [14] have reported $(76.35 \%)$ of their relapse patient put on category II therapy as having a positive outcome. Hence, patients who relapse after receiving a single course of antituberculosis treatment are more likely to be cured with category II retreatment regimen. But this was not the case for failure cases which had worse treatment outcome. The treatment failure was found to be very high in all the three categories (above 10\%) throughout the years. Similar results have been reported under RNTCP from all over the country with a failure rate of $15.5 \%$ for failure group as compared to relapse group $4.8 \%$ [5]. This has already been observed in several studies that have shown that failures are significantly associated with multi drug resistance (MDR) [15-16]. In these categories of patients, the standard retreatment regimen is inadequate and should be assessed for drug resistant tuberculosis and then ultimately make the most of the second line drugs [17-18].

It is a known fact that patients who interrupt their first course of treatment have a significant and consistently higher probability of interrupting a retreatment regimen compared to other cases. In our study we also observed that the frequency of defaulting was more in default cases (13.8\%) than in failure cases $(4.34 \%)$ and relapse cases (3.74\%), though the figure was lower than the national data (18\%) [4]. For these particular cases, treatment adherence is the main solution, apart from this patient's attitude and behaviour towards the disease is also a major factor influencing treatment adherence. There can be many reasons for a patient not co-operating with the treatment. Other risk factors have been described as lack of health knowledge; distance to treatment centre, patient's economic status [19-20]. Migration due to one's work as been the main cause of defaulting among the tuberculosis patients in Sikkim [21]. Studies have shown most defaulters tend to discontinue their treatment again; hence exploring the risk factors for defaulting may help the programme by setting up health education, counseling of the patients, better tracking system of the patients and treatment adherence should be strongly emphasized to them.

\section{Conclusion}

Persistent monitoring of treatment outcomes of relapse, failure and default cases is crucial for improving TB control. The analysis has shown that in Sikkim: relapse cases were the most common retreatment category; patients who relapse after receiving a single course of anti-tuberculosis treatment were more likely to be cured with the Category II retreatment regimen; patients who failed the Category I treatment have a high risk of also failing on the Category II retreatment regimen, and patients who default from a first anti-tuberculosis treatment regimen have a significant risk of also defaulting from the Category II retreatment regimen. Hence, our national TB program should be designed on guidelines where failure cases are prevented from failing again and default cases from defaulting again. Controlling the need for retreatment is the best known strategy in the first place, apart from this continuous monitoring, adherence to treatment and treatment completion is essential to review the tuberculosis control programme in order to improve tuberculosis control.

\section{Competing interests}

The authors declare that they have no competing interests.

\section{Authors' contributions}

Karma G. Dolma concieved, designed, acquired data, analyzed \& interpreted, statistical analysis \& drafted the manuscript. Peggy Dadul, Tsering Laden \& Lalita Singhi acquired data, supervision, critical revision of data. Luna Adhikari conceived \& designed, supervision, critical revision.

J. Mahanta designed, analyzed \& interpreted, supervision

\& critical revision for important intellectual content.

\section{Acknowledgement and funding}

We sincerely thank, JJD Pradhan (ex-STO) Rinzing Bhutia, state tuberculosis officer (STO), the entire staff of state tuberculosis cell and the staff of the district tuberculosis cell for their valuable co-operation. We declare that no funding, direct or indirect to our study has been received.

\section{Publication history}

Received: 22-Feb-2013 Revised: 20-Mar-2013

Re-Revised: 15-Apr-2013 Accepted: 23-Apr-2013

Published: 29-Apr-2013

\section{References}

1. Tewari VK, Pradhan JJD: RNTCP in Sikkim: A success story. NTI Bulletin 2008, 44: 1-10. I Pdf

2. Central Tuberculosis Division (2011) Tuberculosis India: Annual Report of the Revised National Tuberculosis Control Programme. Directorate General of Health Services, Ministry of Health and Family Welfare, Government of India 2011. | Website

3. Central Tuberculosis Division (2012) Tuberculosis India: Annual Report of the Revised National Tuberculosis Control Programme. Directorate General of Health Services, Ministry of Health and Family Welfare, Government of India 2012. I Website

4. World Health Organization: Treatment of tuberculosis. Guidelines for national programmes. WHO/CDS/TB/2003.313. Geneva, Switzerland: WHO, 2003. I Pdf

5. Central Tuberculosis Division (2009) Tuberculosis India: Annual Report of the Revised National Tuberculosis Control Programme. Directorate General of Health Services, Ministry of Health and Family Welfare, Government of India 2009. I Website

6. Directorate General of Health Services. New Delhi: Ministry of Health and Family Welfare, Nirman Bhavan, Gol; 2005. Central TB Division, Technical and Operational Guidelines for Tuberculosis Control. | Website 
Dolma et al. Research Journal of Infectious Diseases 2013,

7. Chandrasekaran V, Gopi PG, Santha T, Subramani R and Narayanan PR: Status of re-registered patients for tuberculosis treatment under DOTS programme. Indian J Tuberc 2007, 54:12-6. I Pdf | PubMed

8. Mehra RK, Dhingra VK, Nish A and Vashist RP: Study of relapse and failure cases of CAT I retreated with CAT II under RNTCP--an eleven year follow up. Indian J Tuberc 2008, 55:188-91. I Pdf | PubMed

9. Azhar GS: DOTS for TB relapse in India: A systematic review. Lung India 2012, 29:147-53. | Article | PubMed Abstract | PubMed Full Text

10. Hong YP, Kim SJ, Lew WJ, Lee SH and Lee EK: Cohort analyses of the treatment of smear-positive pulmonary tuberculosis patients under programme conditions in Korea, 1983-1994. Int J Tuberc Lung Dis 1998, 2:365-71. | Article | PubMed

11. Heldal E, Arnadottir T, Cruz JR, Tardencilla A and Chacon L: Low failure rate in standardised retreatment of tuberculosis in Nicaragua: patient category, drug resistance and survival of 'chronic' patients. Int J Tuberc Lung Dis 2001, 5:129-36. | Article | PubMed

12. Cao JP, Zhang LY, Zhu JQ and Chin DP: Two-year follow-up of directly-observed intermittent regimens for smear-positive pulmonary tuberculosis in China. Int J Tuberc Lung Dis 1998, 2:360-4. | Article | PubMed

13. Central Tuberculosis Division (2010) Tuberculosis India 2010. Annual Report of the Revised National Tuberculosis Control Programme. Directorate General of Health Services, Ministry of Health and Family Welfare, Government of India. I Website

14. Mukherjee A, Sarkar A, Saha I, Biswas B and Bhattacharyya PS: Outcomes of different subgroups of smear-positive retreatment patients under RNTCP in rural West Bengal, India. Rural Remote Health 2009, 9:926. I Article | PubMed

15. Kritski AL, Rodrigues de Jesus LS, Andrade MK, Werneck-Barroso E, Vieira MA, Haffner A and Riley LW: Retreatment tuberculosis cases. Factors associated with drug resistance and adverse outcomes. Chest 1997, 111:1162-7. | Article | PubMed

16. Espinal MA, Kim SJ, Suarez PG, Kam KM, Khomenko AG, Migliori GB, Baez J, Kochi A, Dye C and Raviglione MC: Standard short-course chemotherapy for drug-resistant tuberculosis: treatment outcomes in 6 countries. JAMA 2000, 283:2537-45. | Article | PubMed

17. Espinal MA: Time to abandon the standard retreatment regimen with first-line drugs for failures of standard treatment. Int J Tuberc Lung Dis 2003, 7:607-8. | Article I PubMed

18. Quy HT, Lan NT, Borgdorff MW, Grosset J, Linh PD, Tung LB, van Soolingen $D$, Raviglione M, Co NV and Broekmans J: Drug resistance among failure and relapse cases of tuberculosis: is the standard re-treatment regimen adequate? Int J Tuberc Lung Dis 2003, 7:631-6. | Article I PubMed

19. Bam TS, Gunneberg C, Chamroonsawasdi K, Bam DS, Aalberg O, Kasland $\mathrm{O}$, Shiyalap K and Srisorrachatr S: Factors affecting patient adherence to DOTS in urban Kathmandu, Nepal. Int J Tuberc Lung Dis 2006, 10:270-6. | Article | PubMed

20. Chang KC, Leung CC and Tam CM: Risk factors for defaulting from antituberculosis treatment under directly observed treatment in Hong Kong. Int J Tuberc Lung Dis 2004, 8:1492-8. | Article | PubMed

21. Dolma KG, Adhikari L, Mohapatra PK and Mahanta J: Determinants for the retreatment groups of pulmonary tuberculosis patients treated in a DOTS programme in Sikkim, India. Indian J Tuberc 2011, 58:178-88. I PubMed

\section{Citation:}

Dolma KG, Adhikari L, Dadul P, Laden T, Singhi L and Mahanta J: A study on the assessment of retreatment tuberculosis patients attending the DOTS centre in Sikkim, India from 2002-2010. Research Journal of Infectious Diseases 2013, 1:3.

http://dx.doi.org/10.7243/2052-5958-1-3 